\title{
Sustainability of Biorefinery Processes Based on Baru Biomass Waste
}

\author{
Magale K. D. Rambo, ${ }^{\oplus *, a}$ Michele C. D. Rambo, ${ }^{b}$ Polyana M. Melo, ${ }^{c}$ \\ Nayra Morgana L. de Oliveira, ${ }^{c}$ Yara K. S. Nemet, ${ }^{c}$ Elisandra Scapin, ${ }^{a}$ \\ Guenther C. C. Viana ${ }^{d}$ and Daniel A. Bertuol ${ }^{e}$ \\ aPrograma de Pós-Graduação em Ciências Ambientais, Universidade Federal do Tocantins (UFT), \\ Campus de Palmas, 77001-090 Palmas-TO, Brazil \\ ${ }^{b}$ Instituto Federal do Tocantins (IFTO), Campus de Palmas, 77021-090 Palmas-TO, Brazil \\ 'Programa de Pós-Graduação em Ciência e Tecnologia de Alimentos, \\ Universidade Federal do Tocantins (UFT), 77001-090 Palmas-TO, Brazil \\ ${ }^{d}$ Laboratório de Química, Curso de Engenharia Ambiental, \\ Universidade Federal do Tocantins (UFT), 77001-090 Palmas-TO, Brazil \\ ${ }^{e}$ Laboratório de Processos Ambientais, Universidade Federal de Santa Maria (UFSM), \\ 97105-900 Santa Maria-RS, Brazil
}

\begin{abstract}
The aims of the current study are to investigate the composition of biomass from baru processing and to explore the feasibility of valuing it through the development of bioproducts such as fermentable sugars, furanics and biochar. Baru (Dipteryx alata Vog.) waste (endocarp and mesocarp) has great energetic potential to produce bioproducts due to its chemical composition. Proximate analyses applied to such waste have found low favorable moisture and ash content in it. Bioproduct characterizations after acid hydrolysis have shown that baru endocarp and mesocarp biomass can enable a range of value-added products in biorefinery concepts such as furfural and 5-hydroximetylfurfural (20.0 and 1.5\% yield, respectively), and high sugar content (approximately 19.15 and $38.40 \%$, respectively). Pyrolysis processes also present high biochar content (ca. 48\%), with satisfactory characteristics to be used as fuel, as well as calorific value higher than $30 \mathrm{~kJ} \mathrm{~g}^{-1}$.
\end{abstract}

Keywords: Cerrado, lignin content, sugar content, furanics, biochar

\section{Introduction}

Environment preservation is a recurrent subject in several governmental and industry discussion lines. Chemicals play a key role in all processes; thus they have often been labeled as a major threat to the environment and to humans due to the formation of toxic byproducts and to contamination processes. Compound formation through green chemistry has gained importance in the industrial sector, since it provides new processes that become progressively less harmful to the environment. ${ }^{1}$

Plant species native to Cerrado stand out for their strong social and economic potential, since they are available and renewable raw material to the production of value-added



*e-mail: magalerambo@uft.edu.br
The Cerrado region covers approximately $24 \%$ of the Brazilian territory and is the second-largest biome in South America. This region presents a native fruit known as baru (Dipteryx alata Vog.), ${ }^{3}$ which is widely used by the local population due to its diversified applications; among them one finds food, timber, medicinal and industrial use, landscaping and the recovery of degraded areas. Baru is highly adaptable, and such feature turns it into a producer of high-yield and good-quality fruits and seeds. ${ }^{4}$

This ovoid drupe-type fruit has light brown color and holds a single edible seed, which is commonly known as almond. Baru fruits have fibrous and sweet mesocarp, which can also be consumed; as well as woody endocarp, which has a spongy layer inside and presents industrial potential for coal and biofuel production. ${ }^{5}$ The chemical properties of baru fruits have raised technological interest in their bark (endocarp) and pulp (mesocarp), which are 
mainly composed of starch, lignin, sugars, vitamins and essential oils. ${ }^{5,6}$

Biomass components subjected to hydrolysis are converted into a range of bio-products such as fermentable sugars, furfural (FF) and 5-hydroximetylfurfural (5-HMF) and into a significant number of different types of solid waste. FF can derive from pentoses (i.e., xylose), whereas 5-HMF can derive from hexoses. Both bioproducts are excellent platform chemicals, since they can be transformed into fuel additives such as furfural alcohol, ethyllevulinate, levulinic acid and tetrahydrofuran. ${ }^{7,8}$ The solid residual material that remains after hydrolysis, which is known as residue hydrolyzation $(\mathrm{RH})$ process, is mainly composed of lignin. ${ }^{9}$ This material can be pyrolyzed to enable the production of energy and platform chemicals (bio-oil and biochar).

Therefore, the aims of the current study were to determine the physical-chemical properties of lignocellulosic baru waste and to investigate acid hydrolysis and pyrolysis processes under conditions simulating biorefining processes at full biomass use.

\section{Experimental}

\section{Samples}

Baru (Dipteryx alata Vog.) fruits were collected in Porangatu County, Goiás State, Brazil, in October 2017, and stored in plastic bags. Baru almonds were manually removed with a knife. Fruits were dried in circulation oven (SolidSteel SSD 110L) at $105{ }^{\circ} \mathrm{C}$ for $12 \mathrm{~h}$; mesocarps were manually separated from woody endocarps. After the separation procedure was over, both samples were mill-milled in a willye mill (star FT 50 model, Fortenox); next, they were sieved into 48-mesh particles and stored in hermetically sealed glass vials.

\section{Physical-chemical composition}

\section{Proximate analysis}

According to ASTM D 3173-87, ${ }^{10} 1 \mathrm{~g}$ of sample was heated $\left(105 \pm 5{ }^{\circ} \mathrm{C}\right.$, overnight) in oven (SolidSteel SSD 110L) to determine the moisture content; dried samples were burned in muffle furnace $\left(550 \pm 5{ }^{\circ} \mathrm{C}, 4 \mathrm{~h}\right)$ to determine the ash content (AC). ${ }^{11}$ The volatile matter content (VMC) was determined $\left(750 \pm 10{ }^{\circ} \mathrm{C}\right.$ for $\left.7 \mathrm{~min}\right)$, based on ASTM D 3175-07, ${ }^{12}$ whereas the fixed carbon (FC) content was calculated thorough equation 1 :

$\mathrm{FC}(\%)=100-(\mathrm{AC}+\mathrm{VMC})$

\section{Soxhlet extraction}

A Soxhlet extractor was used in the extraction process; short reaction times $(5 \mathrm{~h})$ were associated with high ethanol concentrations (95\%) in order to enable higher yield rates, based on Rambo et al. ${ }^{13}$ Extractive contents were calculated through equation 2 .

Extrative $(\%)=\frac{\text { mass extraction }}{\text { raw sample mass }} \times 100$

Acid hydrolysis for sugar and lignin determination purposes

Based on the two-stage acid hydrolysis, the extracted sample (300 mg) was subjected to $72 \%$ sulfuric acid $(3 \mathrm{~mL})$ in water bath at $30^{\circ} \mathrm{C}$ for $1 \mathrm{~h}$; the sample was stirred every $10 \mathrm{~min}$. Next, $84 \mathrm{~mL}$ of water was added to the sample, which was autoclaved (vertical autoclave, Phoenix) for $1 \mathrm{~h}$ at $120{ }^{\circ} \mathrm{C}$. Pressure tubes were filtered through medium porosity crucibles (10 to $15 \mu \mathrm{m}$ ) in a vacuum compressor pump (LT 65, Limatec, coupled). ${ }^{14}$

\section{Lignin content}

Acid insoluble lignin (AIL) and acid soluble lignin (ASL) contents in the pre-treated biomass were quantified based on laboratory analytical procedures by NREL. ${ }^{14}$

The insoluble acid waste retained in the filter crucibles contained insoluble lignin. The waste was washed in distilled water in order to fully remove the acid and, subsequently, it was heated to $105 \pm 5{ }^{\circ} \mathrm{C}$. ASL content was measured in a UV-Vis spectrophotometer (HACH/ Germany, DR5000) at wavelength $294 \mathrm{~nm} ; \mathrm{H}_{2} \mathrm{SO}_{4}$ solution at $4 \%$ was used as blank. Total lignin (TL) was the sum of AIL and ASL.

\section{Sugar content}

The hydrolysate $(150 \mu \mathrm{L})$ was mixed with 3,5-dinitrosalicylic acid (DNS) $(2850 \mu \mathrm{L})$, boiled for $5 \mathrm{~min}$ and cooled in ice-water bath for sugar content quantification purposes. A UV-Vis spectrophotometer (HACH / Germany, DR5000) at wavelength $540 \mathrm{~nm}$ was used to measure the absorbance rate; whereas a D-glucose standard curve was generated to determine the reducing sugars (ART). ${ }^{15}$

\section{Hemicellulose and cellulose contents}

Acid (ADF) and neutral detergent fiber (NDF) methodologies were used to determine hemicellulose contents. ${ }^{16}$ Cellulose was calculated based on the difference between hemicellulose and lignin contents.

\section{Pretreament or hydrolysis step}

The 5-hydroxymethylfurfural (5-HMF) and furfural (FF) synthesis was conducted in a round bottom flask 
added with $10 \mathrm{~mL}$ of hydrolysate, $1 \mathrm{~g}$ of ionic liquid (ILs) (1-n-butyl-3-methyl-imidazole bromide [BMIM][Br] and 1-n-butyl-3-methyl-imidazole chloride [BMIM][Cl]), which was subjected to oil bath at 120 and $140{ }^{\circ} \mathrm{C}$ for 1 and $2 \mathrm{~h}$ reaction times, respectively. After reaction time was over, the sample was washed 3 times in ethyl acetate.

\section{Furanic contents}

Phenomenex Luna C18 $5 \mu \mathrm{m}(250 \times 4.6 \mathrm{~mm})$ column and Phenomenex C18 $(4 \times 3.0 \mathrm{~mm})$ pre-column were used to determine 5-HMF and FF, respectively. The adopted eluent flow was $1 \mathrm{~mL} \mathrm{~min}^{-1}$ at $30^{\circ} \mathrm{C}$, and total run time was $15 \mathrm{~min}$. Isocratic dilution was performed with acetonitrile/water solution (1:8 with $1 \%$ acetic acid); the herein adopted detector was UV (SPD-10A) at wavelength $276 \mathrm{~nm}$. Compound concentrations were calculated based on calibration curves generated from the standard solutions; subsequently, they were applied according to equations 3 and $4 .{ }^{17}$

$$
\begin{aligned}
& 5 \text {-HMF yield }(\mathrm{mol} \%)=\frac{(5-\mathrm{HMF} \text { concentration } \times \text { liquid volume }(10 \mathrm{~mL})) / 126}{\mathrm{~g} \text { of cellulose } / 162} \times 100(3) \\
& \text { FF yield }(\mathrm{mol} \%)=\frac{(\text { FF concentration } \times \text { liquid volume }(10 \mathrm{~mL})) / 96}{\mathrm{~g} \text { of hemicellulose } / 132} \times 100
\end{aligned}
$$

Higher heating value (HHV)

Raw biomass (endocarp and mesocarp) heating values and biochar samples were measured based on the model by Dulong modified by Theegala and Midgett, ${ }^{18}$ which is based on the sum of heat values released from the combustion of elements integrating the material, i.e., on the higher calorific value (HCV). The lower calorific value (LCV) was based on the difference between the higher calorific value and the energy retained by the water in form of steam, which is generated from hydrogen combustion and from sample moisture. The model proposed by Dulong is represented by equations 5,6 and 7 .

$$
\begin{aligned}
& \mathrm{HCV}=8.100 \mathrm{C}_{\mathrm{f}}+34.400\left(\mathrm{H}_{\mathrm{f}}-8 / \mathrm{O}_{\mathrm{f}}\right)+2.500 \mathrm{~S}_{\mathrm{f}} \\
& \mathrm{LCV}=\mathrm{HCV}-580 \mathrm{w} \\
& \mathrm{w}=9 \mathrm{H}_{\mathrm{f}}+\mathrm{U}
\end{aligned}
$$

wherein, HCV: higher calorific value $\left(\mathrm{Kcal} \mathrm{kg}^{-1}\right)$; LCV: lower calorific value ( $\left.\mathrm{Kcal} \mathrm{kg}^{-1}\right)$; $\mathrm{C}_{\mathrm{f}}$ : carbon mass fraction in the sample; $\mathrm{H}_{\mathrm{f}}$ : hydrogen mass fraction in the sample; $\mathrm{O}_{\mathrm{f}}$ : oxygen fraction in the sample; $\mathrm{S}_{\mathrm{f}}$ : sulfur mass fraction in the sample; U: moisture fraction; w: water combustion.

\section{Elemental analysis}

Elemental analyses (Elementar-Vario Macro Cube) of raw and biochar samples were conducted to measure the carbon $(\mathrm{C})$, hydrogen $(\mathrm{H})$, azote $(\mathrm{N})$ and sulfur $(\mathrm{S})$ contents.

\section{$\mathrm{pH}$ determination}

Digital pH meter (Akso, AK90) was used to measure sample $\mathrm{pH}$. The samples were added with distilled water at ratio $1: 20(\mathrm{~m} / \mathrm{v})$ for $1.5 \mathrm{~h} .^{19}$

\section{Fourier transform infrared (FTIR) spectroscopy}

Spectra raw biomass (mesocarp and endocarp) and biochar samples were obtained in the mid infrared region (FT-MID) on a single-beam Agilent CARY 630 FTIR spectrometer. The device worked in diffuse reflectance mode, at wavelength ranging from 500 to $4000 \mathrm{~cm}^{-1}$ (total variation) with $0.5 \mathrm{~nm}$ increments; 32 scans were calculated, on average. Diffuse reflectance (R) infrared spectra were transformed into absorbance (A) by using $\mathrm{A}=\log 10(1 / \mathrm{R})$.

\section{Pyrolysis process}

Waste that have remained after the end of the hydrolysis process was used in the pyrolysis process. Samples (30 g) were pyrolyzed in Pyrex tubular fixed-bed reactor at $500{ }^{\circ} \mathrm{C}$ for $30 \mathrm{~min}$. Pyrolysis vapors and aerosols were continuously transferred to chloroform traps at helium flow of $20 \mathrm{~mL} \mathrm{~min}{ }^{-1}$. Solid material produced during pyrolysis was retrieved in a solids separator. Biochar yield (\%) was defined through equation 8 .

Biochar yield $(\%)=\frac{\left(\mathrm{P}_{1}-\mathrm{P}_{0}\right) \times 100}{\text { sample }(\mathrm{g})}$

wherein: $\mathrm{P}_{0}$ : initial mass and $\mathrm{P}_{1}$ : final mass.

\section{Results and Discussion}

\section{Biomass characterization}

Baru (Dipteryx alata Vog.) fruits are found in several regions of Cerrado biome; they can present different chemical composition levels in a single analysis, depending on their growth site. According to Rocha and Santiago, ${ }^{20}$ moisture, ash and carbohydrate composition were 21.05, 1.19 and $65.01 \mathrm{wt} . \%$, respectively. These values referred to endocarp and mesocarp (mixed) composition. Baru mesocarp recorded moisture, ash and carbohydrate composition 13.76, 4.34 and 54.90 wt. $\%,{ }^{21}$ respectively. Another study ${ }^{22}$ recorded values such as 24.45, 2.00 and $22.50 \mathrm{wt} . \%$ for the same parameters.

Results in Table 1 indicate that both residues had low ash content $(<2.7 \%)$. Low ash concentrations are advantageous in pyrolysis processes because they represent 
low probability of ash deposition and incrustation, as well as of oven surface corrosion. ${ }^{13}$ Low ash contents avoid issues such as increased acid consumption in acid hydrolysis processes.

Table 1. Chemical analysis of raw dry biomass

\begin{tabular}{lcc}
\hline Analyses & Endocarp & Mesocarp \\
\hline Moisture / \% & $6.81 \pm 0.11$ & $10.70 \pm 0.02$ \\
Ash / \% & $0.46 \pm 0.01$ & $2.72 \pm 0.01$ \\
VMC / \% & $80.60 \pm 0.46$ & $87.51 \pm 1.50$ \\
FC / \% & $17.25 \pm 0.17$ & $12.41 \pm 0.01$ \\
Organic matter / \% & $97.90 \pm 0.20$ & $99.91 \pm 0.01$ \\
Extractives / \% & $44.20 \pm 7.00$ & $11.30 \pm 1.97$ \\
Lignin / \% & $30.11 \pm 0.55$ & $31.72 \pm 0.67$ \\
Hemicellulose / \% & $6.30 \pm 1.23$ & $33.41 \pm 1.45$ \\
Cellulose / \% & $19.13 \pm 0.87$ & $20.87 \pm 0.94$ \\
ART / \% & $19.15 \pm 1.23$ & $38.40 \pm 0.87$ \\
pH & $6.55 \pm 0.25$ & $5.84 \pm 0.30$ \\
HHV / (kJ g-1) & $21.41 \pm 0.08$ & $19.52 \pm 0.03$ \\
C / \% & $51.61 \pm 0.04$ & $45.81 \pm 0.02$ \\
H / \% & $6.48 \pm 0.09$ & $6.82 \pm 0.02$ \\
O / \% & $41.01 \pm 0.05$ & $43.4 \pm 0.05$ \\
N / \% & $0.27 \pm 0.03$ & $1.02 \pm 0.03$ \\
\hline
\end{tabular}

VMC: volatile matter content; FC: fixed carbon; ART: reducing sugars; HHV: higher heating value.

Low moisture contents $(<11 \%)$ strongly affected the energy efficiency of the fuel material; in addition, they directly affected calorific values. Baru endocarp presented low moisture content and increased HHV; it also recorded the highest fixed carbon content (17.25\%). While its, the baru mesocarp results indicate that the waste can be used for charcoal production purposes. Furthemore, the high volatile matter content (VMC) amount in mesocarp waste suggests that it can be used as energy source.

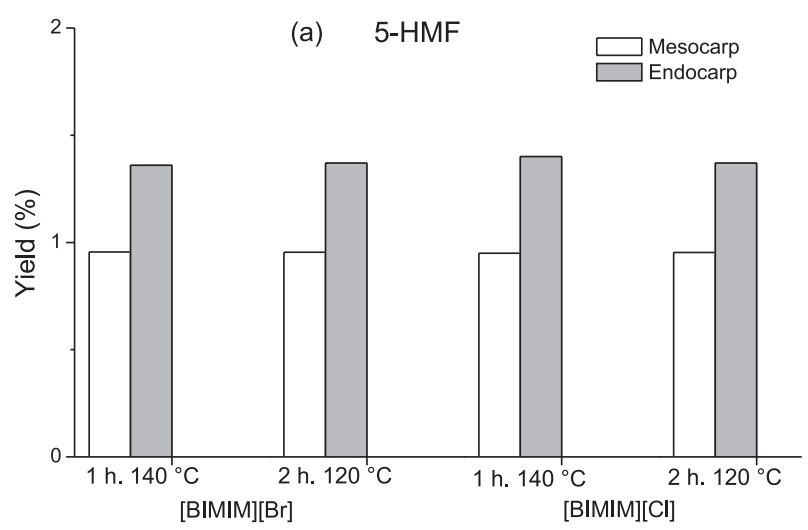

Figure 1. (a) 5-HMF and (b) furfural yields.
High carbon (51.61\%) and low oxygen $(41.01 \%)$ rates also favored increased baru endocarp HHV.

The $\mathrm{pH}$ values have indicated the slightly acidic nature of baru endocarp and mesocarp biomasses, namely: 6.5 and 5.8, respectively. The endocarp presented high total extractive contents ( $>40 \%$ ); this outcome was expected, since baru pulp presents high contents of oils, such as unsaturated oleic, linoleic, fatty acids and $\alpha$-tocopherol. ${ }^{3-23}$ Pinelli et al. ${ }^{24}$ who used ethanol in Soxhlet extraction processes, have found good solvent extraction yield (approximately 46\%), which was very similar to the one recorded in the current study.

High cellulose contents enable a satisfactory rate of bio-products, mainly of 5-HMF. In addition, based on the high lignin contents, pyrolysis can produce satisfactory amounts of biochars.

\section{Furanic compound production}

Some treatments applied to residual biomass enable generating substances that build block components with potential to the synthesis of a whole variety of new important industrial chemical inputs such as FF and 5-HMF.

The 5-HMF production (Figure 1a) recorded for both baru biomass fractions was very low (ca.1.5\%), regardless of the adopted condition (time and temperature) or of LI.

Other studies in the literature ${ }^{25,26}$ have also reported low yield-5-HMF $(<5.0 \%)$-due to residual biomass use. Review studies ${ }^{26}$ have adopted high temperatures $\left(140-270{ }^{\circ} \mathrm{C}\right)$ and short reaction times (10-40 $\mathrm{min}$ ) and recorded 5-HMF yield ranging from 2.4 to $4.9 \%$ for sugarcane bagasse, ${ }^{25}$ maple wood, ${ }^{27}$ wheat straw ${ }^{28}$ and vegetable waste..$^{29}$ According to Nguyen et al. ${ }^{30}$ the recalcitrant and heterogeneous features of raw lignocellulosic materials have resulted in low 5 -HMF. ${ }^{31,32}$

However, a study performed by Zhang et al. ${ }^{33}$ used cellulose as reactant in conversion process conducted in the

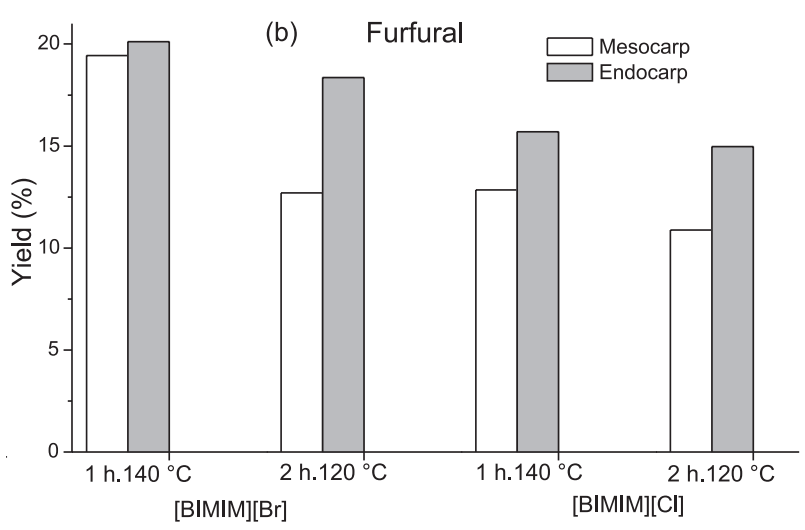


presence of catalysts presenting different Brønsted/Lewis acid and base. The catalysts enabled $42.2 \%$ yield of 5-HMF in the ILs-based system under optimal conditions. ${ }^{33}$ The aforementioned study has observed that higher values of 5-HMF are associated with the presence of catalysts capable of accelerating and directing the reaction, thus avoiding the formation of other major intermediates such as levulinic and formic acids. It happens because, in the presence of catalysts, the catalytic active site has the potential to trigger glucose isomerization via intramolecular hydride displacement and to form free fructose, thus enabling increased 5-HMF yield. ${ }^{34,35}$

However, the herein recorded FF production values (Figure 1b) were close to the one recorded in a study in the literature (21\%), which used ionic acid ([BMIM]Cl) generated from bamboo biomass at $100{ }^{\circ} \mathrm{C}$ for $1.5 \mathrm{~h} .{ }^{36}$ The best FF value found in the current study (20\%) was associated with baru mesocarp subjected to the mildest working condition (the lowest temperature and the shortest reaction time) in bromine base ( $\mathrm{Br})$. FF yield was higher than 5-HMF yield. It happened because the reaction was directed towards FF formation, even in the absence of the catalyst, since furfural is the main pentose degradation product.

\section{Pyrolysis and biochar production}

Approximately $30 \%$ of the mass remained solid after acid hydrolysis, mainly lignin. ${ }^{9}$ This material was pyrolyzed and produced large amounts of char from baru mesocarp and endocarp- 48.5 and $47.9 \%$, respectively. Based on studies available in the literature, biochar yield rates deriving from slow pyrolysis depend on temperature and residence time; besides, they range from 25 to $62 \mathrm{wt} . \%$ when lignocellulosic biomass is used in the process. Biochar yield rates higher than $40 \%$ are associated with biomass pyrolysis with higher lignin content. ${ }^{37}$

Biochar stands out among the main products obtained from baru fractions after slow pyrolysis; Table 2 presents its characteristics. FC results indicate approximately $50 \%$ increase in biochar in comparison to biomass (Table 1); based on this outcome, biochar is relatively more favorable to soil amendment than biomass.

The low ash content $(<0.57 \%)$ in both biochars suggests positive correlation between biochar yield and ash content, since the higher the ash content, the lower the carbon content in biochars.

Based on $\mathrm{pH}$ values, the acid nature of biochars was attributed to low alkali metals and to high lignin content; this finding makes sense, since the raw material is practically formed from the acidic lignin waste. Other
Table 2. Proximate analysis, $\mathrm{pH}$ and calorific value of baru hydrolized biochars

\begin{tabular}{lcc}
\hline Analyses & Mesocarp & Endocarp \\
\hline Moisture / \% & $2.87 \pm 0.07$ & $4.62 \pm 0.09$ \\
Ash / \% & $0.57 \pm 0.02$ & $0.27 \pm 0.01$ \\
$\mathrm{VMC} / \%$ & $24.01 \pm 0.00$ & $26.51 \pm 0.01$ \\
$\mathrm{FC} / \%$ & $75.52 \pm 0.01$ & $72.8 \pm 0.01$ \\
$\mathrm{pH}$ & $5.61 \pm 0.15$ & $4.40 \pm 0.18$ \\
$\mathrm{C} / \%$ & $81.90 \pm 0.84$ & $83.62 \pm 0.36$ \\
$\mathrm{H} / \%$ & $2.53 \pm 0.02$ & $2.79 \pm 0.04$ \\
$\mathrm{~N} / \%$ & $2.07 \pm 0.02$ & $0.55 \pm 0.01$ \\
$\mathrm{O} / \%$ & $11.71 \pm 1.03$ & $12.64 \pm 0.36$ \\
$\mathrm{~S} / \%$ & $1.35 \pm 0.06$ & $0.26 \pm 0.04$ \\
$\mathrm{HHV} /\left(\mathrm{kJ} \mathrm{g}^{-1}\right)$ & $30.48 \pm 0.40$ & $31.13 \pm 0.21$ \\
\hline $\mathrm{VMC}: \mathrm{Volat}^{-\mathrm{m}}$ &
\end{tabular}

VMC: volatile matter content; FC: fixed carbon; HHV: higher heating value.

studies in the literature present biochar $\mathrm{pH}$ values ranging from 4 to $11 .{ }^{38}$

Biochar calorific values help estimating its potential to be used as fuel. Baru waste conversion into biochar increased the HHV (> 10\%); this outcome demonstrates the potential of this waste to be used as solid fuel, since the value recorded for it was close to that of materials often used for the same purpose. ${ }^{38}$

\section{FTIR spectra biochar}

Figure 2 presents functional groups of feedstocks and biochars deriving from baru; these groups show chemical structure transformations after pyrolysis.

Groups observed in regions (3400 and $3000 \mathrm{~cm}^{-1}$ ) associated with $\mathrm{O}-\mathrm{H}$ (probably alcohols and organic acids) and $\mathrm{C}-\mathrm{H}$ (aliphatics) stretching vibration were only found



Figure 2. FTIR of biomass samples and baru biochar. 
in raw feedstock, which indicated one breakage in these groups at high temperatures. ${ }^{37}$ The stretching vibration of heteroaromatic compounds $(\mathrm{C}-\mathrm{O})$ attributed to alcohols, phenols and ethers was not affected by high pyrolysis temperatures. The comparison between raw biomass and biochar showed apparent difference in absorbance intensity between spectra due to the presence of phenolic groups (below $1000 \mathrm{~cm}^{-1}$ ) and carbonyl compounds such as ether, esthers and acids (1000-1250 $\left.\mathrm{cm}^{-1}\right)$. It happened because biochar is mostly composed of lignin and undegraded cellulose. ${ }^{19}$ Aromatic absorption peaks recorded for biochar were mainly observed in the last band. This result indicates that biochar samples faced functional group and heteroatom removal processes that have formed more aromatic structures in biochar. ${ }^{37}$ These results are in compliance with biochar proximate and elemental analysis, which recorded higher $\mathrm{C}$ content and lower $\mathrm{O}$ values than the raw feedstock. ${ }^{37,38}$

Biochar presenting highly-aromatic properties has the potential to be feedstock for materials used in carbon sequestration and activation, as well as chemical reaction catalyst support and metallurgy reducing agent. ${ }^{38}$ Besides, it presents high HHV, as already reported in the literature (Table 2).

\section{Conclusions}

Thus, the use of abundant biomass waste in the present study, namely: baru endocarp and mesocarp, is promising, which turns such waste into a very attractive alternative. The physical-chemical characterization process has shown that this waste can provide a wide range of bioproducts, since it meets biorefinery concepts such as high reducing sugar content $(>38 \%)$, considerable furfural content $(>20 \%)$, and low moisture and ash content. High lignin contents contribute to high biochar concentrations (ca. 48\%); thus, biochar has the potential to be used as fuel, since it records high calorific value $\left(>30 \mathrm{~kJ} \mathrm{~g}^{-1}\right)$.

\section{Acknowledgments}

The authors are grateful to the Institutional Program of UFT and Palmas/IFTO for the support given to the current study.

\section{References}

1. Sheldon, R. A.; Woodley, J. M.; Chem. Rev. 2017, 118, 801.

2. Lancefield, C. S.; Panovic, I.; Deuss, P. J.; Barta, K.; Westwood, N. J.; Green Chem. 2017, 19, 202.

3. Fetzer, D. L.; Cruz, P. N.; Hamerski, F.; Corazza, M. L.; J. Supercrit. Fluids 2018, 137, 23.
4. Moraes, C.; Anjos, J. L. V.; Maruno, M.; Alons, A.; Rocha-Filho, P.; Asian J. Pharm. Sci. 2018, 13, 183.

5. Takemoto, E.; Okada, I.; Rev. Inst. Adolfo Lutz 2001, 60, 113.

6. Fernandes, D. C.; Freitas, J. B.; Czeder, L. P.; Naves, M. M. V.; J. Sci. Food Agric. 2010, 90, 1650.

7. Luo, Y.; Li, Z.; Li, X.; Liu, X.; Hu, C.; Catal. Today 2018, 319 , 14.

8. Scapin, E.; Rambo, M. K. D.; Viana, G. C. C.; Marasca, N.; Lacerda, G. E.; Rambo, M. C. D.; Fernandes, R. M. N.; Food Sci. Technol., in press, DOI: http://dx.doi.org/10.1590/ fst.04419.

9. Rambo, M. K. D.; Novotny, E. H.; Canellas, L. P.; Aguiar, N. O.; Auccaise, R.; Rambo, M. C. D.; J. Chem. Chem. Eng. 2014, 8, 960.

10. ASTM D 3173-87: Standard Method for Determination of Moisture Content in Biomass, West Conshohocken, 2003.

11. ASTM D 3174-04: Standard Method for Ash in The Analysis Sample of Coal and Coke, West Conshohocken, 2004.

12. ASTM D 3175-07: Standard Method for Volatile Matter in The Analysis Sample of Coal, West Conshohocken, 2007.

13. Rambo, M. K. D.; Alexandre, G. P.; Rambo, M. C. D.; Alves, A. R.; Garcia, W. T., Baruque, E.; Food Sci. Technol. 2015, 35, 605.

14. NREL/TP-510-42618: Determination of Structural Carbohydrates and Lignin in Biomass, Colorado, USA.

15. Weerachanchai, P.; Lee, J. M.; Bioresour. Technol. 2014, 169, 336.

16. Trujillo, A. I.; Marichal, M. J.; Carriquiry, M.; Anim. Feed Sci. Technol. 2010, 161, 49.

17. Cai, C.; Qiying, L.; Tan, J.; Wang, T.; Zhang, Q.; Longlong, M.; BioResources 2017, 12, 1201.

18. Theegala, C.; Midgett, J. S.; Bioresour. Technol. 2012, 107, 456.

19. Bardalai, M.; Mahanta, D. K.; Mater. Today: Proc. 2018, 5, 2089.

20. Rocha, L. S.; Santiago, R. A. C.; Food Sci. Technol. 2009, 29, 820.

21. Alves, M. A.; Mendonça, A. L.; Caliari, M.; Santiago, R. A. C.; Pesq. Agropec. Trop. 2010, 40, 266.

22. Lima, J. C. R.; Freitas, J. B.; Czeder, L. P.; Fernandes, D. C.; Naves, M. M. V.; B. Ceppa 2010, 28, 331.

23. Nunes, A. A.; Favaro, S. P.; Miranda, C. H. B.; Neves, V. A.; J. Sci. Food Agric. 2017, 97, 151.

24. Pinelli, L. L. O.; Carvalho, M. V.; Aguiar, L. A.; Oliveira, G. T.; Celestino, S. M. C.; Botelho, R. B. A.; Chiarello, M. D.; LWT - Food Sci. Technol. 2015, 60, 50.

25. Iryani, D. A.; Kumagai, S.; Nonaka, M.; Sasaki, K.; Hirajima, T.; Procedia Earth Planet. Sci. 2013, 6, 441.

26. Yu, I. K. M.; Tsang, D. C. W.; Bioresour. Technol. 2017, 238, 716.

27. Cai, C. M.; Zhang, T.; Kumar, R.; Wyman, C. E.; Green Chem. 2013, 15, 3140.

28. Yemis, O.; Mazza, G.; Bioresour. Technol. 2012, 109, 215. 
29. Yu, I. K. M.; Tsang, D. C. W.; Yip, A. C. K.; Chen, S. S.; Ok, Y. S.; Poon, C. S.; Bioresour. Technol. 2016, 219, 338.

30. Nguyen, C. V.; Lewis, D.; Chen, W. H.; Huang, H. W.; ALOthman, Z. A.; Yamauchi, Y.; Wu, K. C. W.; Catal. Today 2016, 278, 344.

31. Sievers, C.; Valenzuela-Olarte, M. B.; Marzialetti, T.; Musin, I.; Agrawal, P. K.; Jones, C. W.; Ind. Eng. Chem. 2009, 48, 1277.

32. Vanoye, L.; Fanselow, M.; Holbrey, J. D.; Atkins, M. P.; Seddon, K. R.; Green Chem. 2009, 11, 390.

33. Zhang, Y.; Chen, Y.; Pan, J.; Liu, M.; Jin, P.; Yan, Y.; Chem. Eng. J. 2017, 313, 1593.
34. Yu, S. B.; Zang, H. J.; Yang, X.-L.; Zhang, M. C.; Xie, R. R.; Pei-Fei Yu, P. F.; Chin. Chem. Lett. 2017, 27, 1479.

35. Ståhlberg, T.; Rodriguez-Rodriguez, S.; Fristrup, P.; Riisager, A.; Chem. Eur. J. 2011, 17, 1456.

36. Wu, C.; Chen, W.; Zhong, L.; Peng, X.; Sun, R.; Fang, J.; Zheng, S.; J. Agric. Food Chem. 2014, 62, 7430.

37. Li, S.; Chen, G.; Waste Manage. 2018, 78, 198.

38. Wang, H.; Wang, X.; Cui, Y.; Xue, Z.; Ba, Y.; Bioresour. Technol. 2018, 263, 444.
Submitted: February 8, 2019

Published online: July 23, 2019 